\title{
The relationship of retinal vessel diameter to changes in diabetic nephropathy structural variables in patients with type 1 diabetes
}

\author{
R. Klein • M. D. Knudtson • B. E. K. Klein • \\ B. Zinman • R. Gardiner $\cdot$ S. Suissa • A. R. Sinaiko • \\ S. M. Donnelly $\cdot$ P. Goodyer $\cdot$ T. Strand $\cdot$ M. Mauer
}

Received: 23 February 2010 /Accepted: 22 March 2010/Published online: 1 May 2010

(C) Springer-Verlag 2010

\begin{abstract}
Aims/hypothesis We examined whether retinal vessel diameter in persons with type 1 diabetes mellitus is associated with changes in subclinical anatomical and functional indicators of diabetic nephropathy.
\end{abstract}

R. Klein $(\bowtie) \cdot$ M. D. Knudtson • B. E. K. Klein

Department of Ophthalmology and Visual Sciences,

University of Wisconsin-Madison,

610 North Walnut Street, Fourth Floor WARF,

Madison, WI 53726-2397, USA

e-mail: kleinr@epi.ophth.wisc.edu

B. Zinman

Department of Medicine, Leadership Sinai Center for Diabetes, Mount Sinai Hospital, University of Toronto,

Toronto, ON, Canada

R. Gardiner

Department of Medicine, McGill University,

Montreal, QC, Canada

S. Suissa

Departments of Epidemiology and Biostatistics and Medicine,

McGill University,

Montreal, QC, Canada

A. R. Sinaiko $\cdot$ T. Strand $\cdot$ M. Mauer

Department of Pediatrics, University of Minnesota,

Minneapolis, MN, USA

S. M. Donnelly

Department of Medicine, Saint Michael's Hospital,

University of Toronto,

Toronto, ON, Canada

P. Goodyer

Departments of Pediatrics and Epidemiology and Biostatistics,

McGill University,

Montreal, QC, Canada
Methods Persons with type 1 diabetes mellitus had gradable fundus photographs and renal biopsy data at baseline and 5-year follow-up $(n=234)$. Retinal arteriolar and venular diameters were measured at baseline and follow-up. Central retinal arteriole equivalent (CRAE) and central retinal venule equivalent (CRVE) were computed. Baseline and 5-year follow-up renal structural variables were assessed by masked electron microscopic morphometric analyses from percutaneous renal biopsy specimens. Variables assessed included: mesangial fractional volume, glomerular basement membrane width, mesangial matrix fractional volume and glomerular basement membrane width composite glomerulopathy index.

Results While controlling for other covariates, baseline CRAE was positively associated with change in the glomerulopathy index over the 5-year period. Change in CRAE was inversely related to a change in mesangial matrix fractional volume and abnormal mesangial matrix fractional volume, while change in CRVE was directly related to change in the volume fraction of cortex that was interstitium [ $V v_{(\text {Int/cortex })]}$ over the 5-year period. Baseline CRAE or CRVE or changes in these diameters were not related to changes in other anatomical or functional renal endpoints.

Conclusions/interpretation Independently of other factors, baseline CRAE correlated with changes in glomerulopathy index, a composite measure of extracellular matrix accumulation in the mesangium and glomerular basement membrane. A narrowing of the CRAE was related to mesangial matrix accumulation. Changes in CRVE were related to changes in $V v_{\text {(Int/cortex), a measure of interstitial }}$ expansion in persons with type 1 diabetes mellitus.

Keywords Epidemiology - Microvascular disease . Nephropathy - Retinal blood vessel diameters .

Risk indicators - Type 1 diabetes mellitus 


\begin{tabular}{|c|c|}
\hline \multicolumn{2}{|c|}{ Abbreviations } \\
\hline CRAE & Central retinal arteriole equivalent \\
\hline CRVE & Central retinal venule equivalent \\
\hline ETDRS & $\begin{array}{l}\text { Early Treatment Diabetic Retinopathy } \\
\text { Study }\end{array}$ \\
\hline GBM & Glomerular basement membrane \\
\hline $\mathrm{AH}$ & Index \\
\hline RASS & Renin-Angiotensin System Study \\
\hline$\delta v_{\text {(PGBN }}$ & $\begin{array}{l}\text { Surface density (surface/volume) of } \\
\text { peripheral glomerular capillary } \\
\text { glomerular basement membrane per } \\
\text { glomerulus }\end{array}$ \\
\hline$V v_{\text {(Int/cortex) }}$ & $\begin{array}{l}\text { Volume fraction of cortex that was } \\
\text { interstitium }\end{array}$ \\
\hline$V v_{\text {(Mes } / \mathrm{g}}$ & $\begin{array}{l}\text { Mesangial fractional volume per } \\
\text { glomerulus }\end{array}$ \\
\hline$V v_{(\mathrm{MM} / \mathrm{s}}$ & $\begin{array}{l}\text { Mesangial matrix fractional volume } \\
\text { per glomerulus }\end{array}$ \\
\hline WESD & $\begin{array}{l}\text { Wisconsin Epidemiologic Study of } \\
\text { Diabetic Retinopathy }\end{array}$ \\
\hline
\end{tabular}

\section{Introduction}

Despite intensive glycaemic and blood pressure control, diabetic nephropathy remains an important cause of morbidity and death in persons with type 1 diabetes mellitus [1-6]. For development of preventive approaches at an early reversible stage of the disease, it is imperative to detect persons at risk of diabetic nephropathy prior to development of clinical signs of glomerulopathy [6]. It is therefore important to anticipate progression of diabetic nephropathy at its preclinical stages. In particular, renal lesions, through much of the natural history of diabetic nephropathy, develop in clinical silence (Fig. 1) [7-9]. Because carefully measured renal biopsies are not likely to become standard in the care of persons with type 1 diabetes mellitus and because renal lesions may already be present before standard tests of renal dysfunction (e.g. microalbuminuria) reveal them, it is important to have earlier risk predictors of diabetic nephropathy [7]. Additional indicators are also needed because microalbuminuria, although useful, is an imprecise predictor of progression to proteinuria. We have previously reported significant associations between diabetic retinopathy and preclinical morphological changes related to diabetic nephropathy in baseline assessments of normoalbuminuric, normotensive type 1 diabetes mellitus patients in the Renin-Angiotensin System Study (RASS) [10]. Evidence suggests that an additional measurement, assessment of retinal vessel diameter, might also be a useful predictor of chronic kidney disease in patients with type 1 diabetes mellitus $[11,12]$. In this report, we examine whether retinal vessel diameter (Fig. 2) in RASS patients is associated with changes in subclinical anatomical and functional signs of diabetic nephropathy.

\section{Methods}

Description of cohort The RASS was a parallel, doubleblind, placebo-controlled, multi-centre clinical trial of diabetic nephropathy primary prevention and retinopathy development and progression conducted at three clinical centres in Minneapolis (MN, USA), Montreal (QC, Canada) and Toronto (ON, Canada). The study design and cohort description have been detailed elsewhere [13]. All data were collected with Institutional Review Board approval in conformity with all federal, state and provincial laws, and the study was in adherence with the tenets of the Declaration of Helsinki as revised in 1983. Informed consent was obtained. Participants were 15 years of age or older, with type 1 diabetes duration of 2-20 years and disease onset before the 45th birthday. All participants were normotensive ( $\mathrm{BP}<135 / 85 \mathrm{mmHg}$ ), normoalbuminuric (AER $<20 \mu \mathrm{g} / \mathrm{min}$ on at least two of three timed

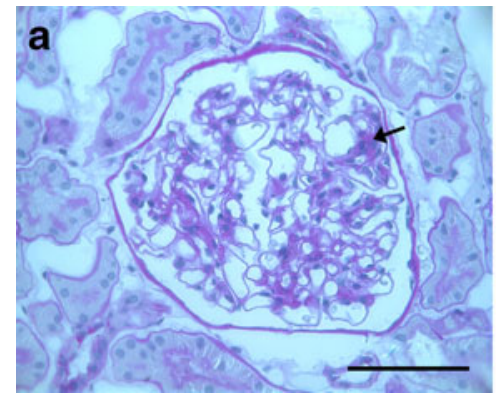

Fig. 1 Photomicrographs from three separate baseline biopsies of glomerular tissues for light microscopy. Biopsies were fixed in Zenker's solution, embedded in paraffin and stained with periodic acid-Schiff's (PAS). a Glomerulus in which the mesangium (black arrow) appears normal. b Glomerulus with mild mesangial expansion
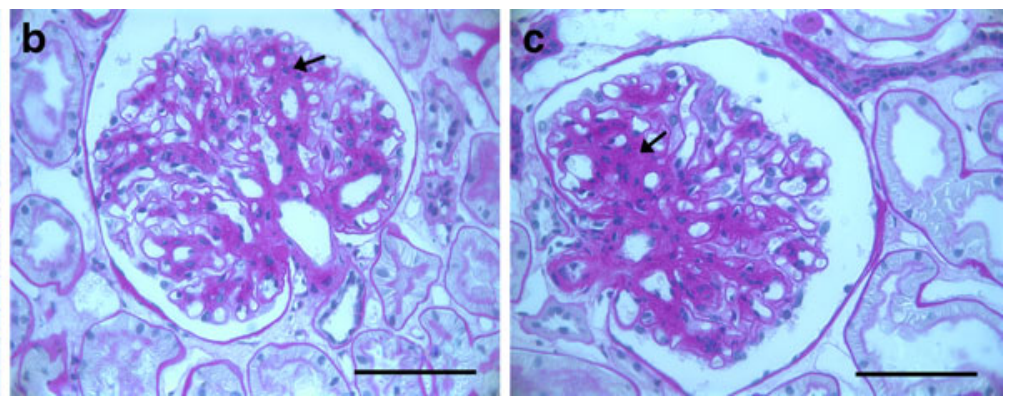

with increased PAS-positive matrix material between the capillary loops and branching from the base of the glomerulus (hilus) to the periphery (black arrow). c Glomerulus with moderate mesangial expansion (black arrow). Scale bars, $50 \mu \mathrm{m}$ 

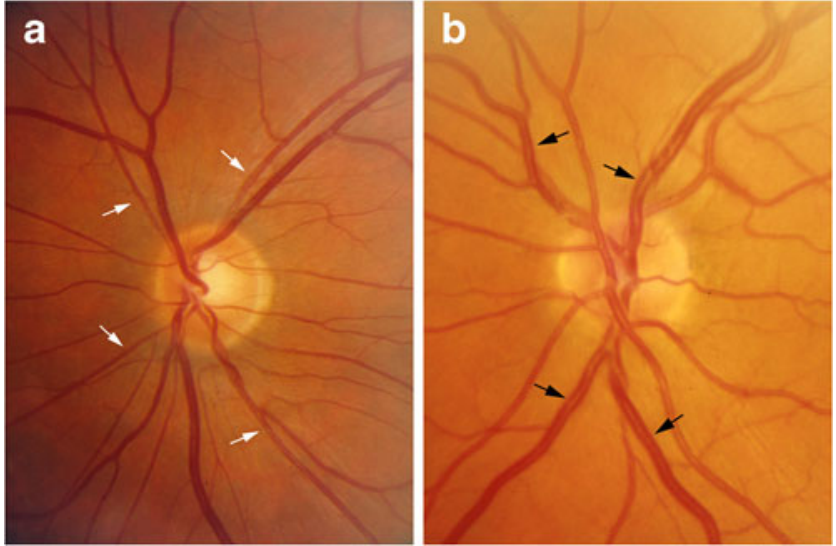

Fig. 2 a Retinal image of left eye showing narrow retinal arterioles (white arrows), CRAE $99 \mu \mathrm{m}$, mean (SD) in the RASS 159 (13) $\mu \mathrm{m}$, and normal retinal venules, CRVE $222 \mu \mathrm{m}$, mean (SD) in the RASS $228(22) \mu \mathrm{m}$. b Retinal image of a left eye showing wide retinal venules (black arrows), CRAE $177 \mu \mathrm{m}$, CRVE $304 \mu \mathrm{m}$, and normal retinal arterioles

overnight urine collections) and had normal or increased GFR $\left(\geq 90 \mathrm{ml} \mathrm{min}^{-1} 1.73 \mathrm{~m}^{-2}\right.$ ). Participants $(n=285)$ were randomised into one of the following three treatment groups: losartan (angiotensin-receptor blocker), enalapril (ACE inhibitor) or placebo [13].

Blood pressure, weight, height and retinal measurements The baseline examination included measurement of BP in a seated position after resting for $5 \mathrm{~min}$, using an automated device (DinaMap Monitor 18465X; Critikon, Palatine, IL, USA). Height and weight were measured according to standard anthropometric procedures. Pupils were dilated and $30^{\circ}$ colour stereoscopic fundus photographs were taken of the seven standard fields as defined in the Early Treatment Diabetic Retinopathy Study (ETDRS) protocol [14]. The photographs were graded in a masked fashion by the University of Wisconsin Ocular Epidemiology Reading Center using the modified Airlie House classification scheme and the ETDRS retinopathy severity scale. Grading protocols and retinopathy severity scales have been described in detail elsewhere $[14,15]$. Diabetic retinopathy severity, based on the more severe eye, was grouped as follows: none (level 10), mild diabetic retinopathy (levels 20-43) and moderate to severe diabetic retinopathy (levels $\geq 47$ ).

Retinal vessel diameters were measured at baseline and at the 5-year follow-up RASS examinations using a computerassisted technique based on a standard protocol, according to which retinal photographs of field 1 (centred at the optic nerve head) were converted to digital images by a high-resolution scanner using identical settings for all photographs [16]. Retinal vessel measurements were done independently for each examination and each eye. Trained graders who were masked to participant characteristics measured the diameters of all arterioles and venules coursing through a specified area of a half- to a whole disc diameter surrounding the optic disc by means of a software program (University of WisconsinMadison, Madison, WI, USA). On average, between 7 and 14 arterioles and an equal number of venules were measured per eye. Individual arteriolar and venular measurements were combined into summary indices reflecting the average retinal arteriolar, i.e. central retinal arteriole equivalent (CRAE), and retinal venular, i.e. central retinal venule equivalent (CRVE), diameter of an eye based on the Parr-Hubbard-Knudtson formula [17]. Graders regularly participated in quality control exercises; the inter- and intra-grader variability was small (interclass and intraclass correlations $>0.90$ for CRAE and CRVE).

Measures of renal function and glycaemia GFR was estimated at baseline and follow-up by plasma disappearance of non-radioactive iohexol (Omnipaque 300; Shearing Plough Welwyn Garden City, UK) as detailed elsewhere and expressed in millilitres per minute adjusted up to $1.73 \mathrm{~m}^{2}$ $[18,19]$. AER was measured in timed overnight urine collections using a sensitive fluorescence immunoassay [20] and expressed in micrograms per minute. Normoalbuminuria was defined as having at least two of three AER readings $<20 \mu \mathrm{g} / \mathrm{min}$. $\mathrm{HbA}_{1 \mathrm{c}}$ was measured by HPLC (Diamat $\mathrm{HbA}_{1 \mathrm{c}}$ analyser; Bio-Rad, Hercules, CA, USA) until April 2002, when the Tosoh method was introduced (Tosoh Medics, San Francisco, CA, USA) [21].

Electron microscopy Percutaneous renal biopsies were obtained within 6 months prior to baseline and at follow-up 5 years after randomisation [22]. Tissue processing was as described elsewhere [10]. The centre-most intact glomeruli in the electron microscopy blocks were selected for study and an image calibration grid was obtained at the beginning of each microscopy session [8]. Electron microscopy digital images (magnification $\times 3,900$ ) stored in tagged image file format (Photoshop 6.0; Adobe, San Jose, CA, USA) were used to build montages of entire glomerular cross-sections, on which counting grids were superimposed. These montages were used to measure the fraction of the glomerulus occupied by the mesangium or the mesangial fractional volume per glomerulus $\left(V v_{\text {[Mes/glom] }]}\right)$, the mesangial matrix fractional volume per glomerulus $\left(V v_{[\mathrm{MM} / \text { glom] }}\right)$, the mesangial cell fractional volume and the surface density (surface/volume) of peripheral glomerular capillary glomerular basement membrane (GBM) per glomerulus $\left(S v_{\text {[PGBM/glom] }}\right)$ [8, 10, 23-27]. After the centre-most glomerulus in a block was randomly entered, 10-20 evenly spaced digital images representing an unbiased systematic sample of approximately $30 \%$ of the glomerular profile were obtained at magnification $\times 11,000$ for measurement of GBM width $[8,23,25,26]$ and mesangial composition [8, 10, 27]. 
A glomerulopathy index, expressed as GBM width/10+ $\left[V v_{(\mathrm{MM} / \mathrm{glom})} \times 100\right]$ and representing a composite expression of glomerular extracellular matrix accumulation in diabetes, was computed using the formula as described by Rudberg et al. [28]. All electron microscopy measurements were done by a single masked observer.

Light microscopy Zenker's fixed periodic acid-Schiff's stained light microscopy slides were randomly selected to determine the index of arteriolar hyalinosis (IAH) in all cortical arterioles $\leq 1$ average tubular diameter in size, based on the fraction of each arteriolar wall replaced by hyaline as simultaneously estimated by two masked observers. IAH was calculated as published [23]. Volume fraction of cortex that was interstitium $\left(V v_{[\text {[nt/cortex] })}\right.$ and volume fraction of cortical tubules per total tubules that were atrophic were estimated by a masked observer at magnification $\times 300$ by point counting [29].

Statistics Statistical analyses were conducted in SAS version 9 (SAS Institute, Cary, NC, USA). Means were compared for statistically significant differences by the $t$ test and ANOVA when two or more than two groups, respectively, were involved. Pearson correlation coefficients were computed for pairwise associations of variables. Multivariable associations between anatomical and functional renal endpoints (and changes in these measures), and CRAE, CRVE and other independent variables such as age, sex, duration of diabetes, $\mathrm{HbA}_{1 \mathrm{c}}$, BP and body mass were explored by multiple linear regression. Similarly, multivariable relationships between anatomical and functional renal characteristics defined as normal or abnormal, and CRAE or CRVE and other independent variables were evaluated by logistic regression, with selected covariates in the model chosen because they were statistically significantly associated with the specific outcome.

\section{Results}

Characteristics of the cohort baseline examination Of the 285 participants, one had insufficient glomeruli for renal morphometric measurements, 28 had renal biopsy data without gradable fundus photographs for retinal vessel measurement and 257 had gradable fundus photographs and biopsy data at baseline. Persons with gradable fundus photographs and biopsy data were older than those without gradable fundus photographs and biopsy data $(p=0.002)$; there were no statistically significant differences between groups for other characteristics [10].

Baseline renal and retinal characteristics of the cohort are presented in Table 1 for 257 of the 285 persons with data available for vessel measurement and at least one of the anatomical or functional measures of diabetic nephropathy. The cohort had a mean age of $30.2 \pm 9.6$ years, a mean duration of type 1 diabetes mellitus of $11.3 \pm 4.7$ years and a mean $\mathrm{HbA}_{1 \mathrm{c}}$ level of $8.5 \pm 1.6 \%$. Ninety per cent of the cohort had no $(34.6 \%)$ or mild $(55.3 \%)$ diabetic retinopathy (Table 1).

Relationships between both CRAE and CRVE and change in renal endpoints Of the 257 participants with gradable retinal vessel measurements and biopsy data at baseline, 234 had gradable fundus photographs and biopsy data at follow-up. Persons with biopsy data at follow-up were younger than those without ( $p=0.03$ ); additionally, persons without follow-up biopsy data and gradable fundus photographs had larger baseline $V v_{\text {(Mes/glom) }}(p=0.04)$ and $V v_{\text {(MM/glom })}(p=0.002)$ than those with biopsy data. Otherwise, there were no statistically significant differences between groups for other characteristics [10].

Table 1 Baseline characteristics of the RASS cohort

\begin{tabular}{|c|c|}
\hline Variable & Mean $(\mathrm{SD})$ or $\%$ \\
\hline Age (years) & $30.2(9.6)$ \\
\hline Male sex $(\%)$ & 48 \\
\hline Diabetes duration (years) & $11.3(4.7)$ \\
\hline $\mathrm{HbA}_{1 \mathrm{c}}(\%)$ & $8.5(1.6)$ \\
\hline Body mass index $\left(\mathrm{kg} / \mathrm{m}^{2}\right)$ & $25.8(3.7)$ \\
\hline Systolic blood pressure (mmHg) & $120(12)$ \\
\hline Diastolic blood pressure (mmHg) & $70(8)$ \\
\hline Mean arterial blood pressure $(\mathrm{mmHg})$ & $87(9)$ \\
\hline Serum creatinine $(\mu \mathrm{mol} / \mathrm{l})$ & $71.5(12.5)$ \\
\hline GFR $\left(\mathrm{ml} \mathrm{min} \min ^{-1} 1.73 \mathrm{~m}^{-2}\right)$ & $129(20)$ \\
\hline Albumin excretion rate $(\mu \mathrm{g} / \mathrm{min})$ & $6.4(5.9)$ \\
\hline$V v_{(\text {Mes/glom) }}{ }^{\mathrm{a}}$ & $0.21(0.04)$ \\
\hline$V v_{(\mathrm{MM} / \mathrm{glom})}^{\mathrm{a}}$ & $0.11(0.03)$ \\
\hline Mesangial cell fractional volume/glomerulus ${ }^{\mathrm{a}}$ & $0.072(0.20)$ \\
\hline GBM width $^{\mathrm{a}}(\mathrm{nm})$ & $476(92)$ \\
\hline$S v_{\left(\text {PGBM }^{\mathrm{b}} / \mathrm{glom}\right)}^{\mathrm{a}}$ & $0.13(0.02)$ \\
\hline$V v_{\text {(Int/cortex) }}{ }^{\mathrm{b}}$ & $0.110(0.036)$ \\
\hline $\begin{array}{l}\text { Volume fraction of cortical tubules per total } \\
\text { of atrophic tubules }\end{array}$ & $0.004(0.019)$ \\
\hline $\mathrm{IAH}^{\mathrm{d}}$ & $1.1(0.2)$ \\
\hline Glomerulopathy index $^{\mathrm{a}}$ & $58.1(10.6)$ \\
\hline \multicolumn{2}{|l|}{ Diabetic retinopathy severity } \\
\hline None $(\%)$ & 34.6 \\
\hline Mild (\%) & 55.3 \\
\hline Moderate to severe $(\%)$ & 10.2 \\
\hline $\operatorname{CRAE}(\mu \mathrm{m})$ & $159(13)$ \\
\hline CRVE $(\mu \mathrm{m})$ & $228(22)$ \\
\hline Participants, total: $n=257$ & \\
\hline
\end{tabular}

${ }^{\mathrm{a}} n=256 ;{ }^{\mathrm{b}} n=223 ;{ }^{\mathrm{c}} n=210$;

${ }^{\mathrm{d}} n=231$ 
The univariate relationships of baseline retinal characteristics to changes in renal endpoints are presented in Table 2. CRAE was associated with change in glomerulopathy index and abnormal glomerulopathy index, while CRVE was associated with change in $V v_{(\mathrm{MM} / \mathrm{glom})}, S v_{(\mathrm{PGBM} / \mathrm{glom})}$ and glomerulopathy index, and abnormal glomerulopathy index. Relationships of CRAE with changes in renal endpoints, controlling for other factors, are presented in Tables 3 and 4. While controlling only for duration of diabetes, CRAE was associated with change in GBM width, $V v_{(\mathrm{MM} / \text { glom) }}$, abnormal glomerulopathy index and $S v_{\text {(PGBM/glom) }}$. The relationship of CRAE with change in glomerulopathy index remained statistically significant after adding other covariates to the model. These relationships did not change when severity of diabetic retinopathy was added to the models (data not shown). Other relationships between CRAE and changes in renal structural endpoints were not statistically significant.

While controlling for duration of diabetes, CRVE was positively associated with change in $V v_{(\mathrm{MM} / \mathrm{glom})}$, glomerulopathy index and $S v_{(\mathrm{PGBM} / \text { glom })}$, and with the incidence of abnormal $S v_{\text {(PGBM/glom) }}$ and abnormal glomerulopathy index (Tables 3 and 4). None of these relationships remained statistically significant while controlling for other covariates in the model.

Relationships between changes in both CRAE and CRVE, and changes in renal endpoints Changes in CRAE over the 5 -year period were related to changes in $V v_{(\mathrm{MM} / \mathrm{glom})}$ $(r=-0.14, p=0.04)$ and incident abnormal $V v_{(\mathrm{MM} / \mathrm{glom})}$ ( $r=-0.17, p=0.03$ ), while changes in CRVE were related to changes in $V v_{\text {(Int/cortex) }}(r=0.20, p<0.01)$. The relation of changes in CRAE remained associated with changes in $V v_{\text {(MM/glom) }}$, incident abnormal $V v_{\text {(MM/glom) }}$ and the relation between changes in CRVE and changes in $V v_{\text {(Int/cortex) }}$, while controlling for other risk factors (data not shown). Changes in CRAE or CRVE were not statistically significantly associated with changes in other renal variables (data not shown).

\section{Discussion}

Changes in retinal vessel diameters occur early in the course of type 1 diabetes mellitus, possibly reflecting structural and/or functional alterations resulting from changes in retinal blood flow and the effects of chronic hyperglycaemia, inflammation and endothelial dysfunction $[30,31]$. Retinal arteriolar narrowing (a small CRAE), for example, is thought to be related to cumulative small vessel damage from the effects of hypertension, while retinal venular widening (a large CRVE) has been thought to reflect retinal hyperperfusion and/or lactic acidosis associated with hyperglycaemia and hypoxia (Fig. 2) [16, 30, 31]. In persons with type 1 diabetes mellitus, narrower retinal arteriolar and wider retinal venular diameters are thought to
Table 2 Correlations of CRAE and CRVE at baseline with change in diabetic nephropathy measures and incident abnormal values over 5-year follow-up

\footnotetext{
${ }^{a}$ Numbers at risk vary due to gradable measurement of nephropathy measures and patients with prevalent abnormal values at baseline

${ }^{\mathrm{b}}$ Pearson correlation for continuous measures (top ten lines) and Spearman correlation for categorical measures (bottom six lines)

${ }^{\mathrm{c}}$ Mesangial cell fractional volume/ glomerulus

${ }^{\mathrm{d}}$ Volume fraction of cortical tubules per total of atrophic tubules
}

\begin{tabular}{|c|c|c|c|c|c|}
\hline \multirow[t]{2}{*}{ Variable } & \multirow[t]{2}{*}{ Participants at risk, $n^{\mathrm{a}}$} & \multicolumn{2}{|l|}{ CRAE } & \multicolumn{2}{|l|}{ CRVE } \\
\hline & & $r^{\mathrm{b}}$ & $p$ value & $r^{\mathrm{b}}$ & $p$ value \\
\hline \multicolumn{6}{|l|}{ Change } \\
\hline GFR & 236 & -0.03 & 0.61 & 0.00 & 0.98 \\
\hline AER & 234 & 0.00 & 0.96 & 0.01 & 0.93 \\
\hline$V v_{\text {(Mes/glom) }}$ & 234 & 0.08 & 0.20 & 0.07 & 0.28 \\
\hline$V v_{(\mathrm{MM} / \mathrm{glom})}$ & 234 & 0.12 & 0.07 & 0.13 & 0.05 \\
\hline$V v_{\text {(MC/glom })^{\mathrm{c}}}$ & 234 & -0.02 & 0.71 & -0.00 & 0.99 \\
\hline GBM width (nm) & 234 & 0.11 & 0.08 & 0.10 & 0.12 \\
\hline$S v_{(\mathrm{PGBM} / \mathrm{glom})}$ & 234 & -0.11 & 0.09 & -0.16 & 0.02 \\
\hline$V v_{\text {(Int/cortex) }}$ & 183 & -0.03 & 0.64 & 0.08 & 0.26 \\
\hline$V v_{(\mathrm{AT} / \mathrm{TT})}{ }^{\mathrm{d}}$ & 165 & -0.09 & 0.23 & -0.011 & 0.16 \\
\hline Glomerulopathy index & 234 & 0.14 & 0.03 & 0.13 & 0.04 \\
\hline \multicolumn{6}{|l|}{ Abnormal values } \\
\hline$V v_{\text {(Mes/glom) }}(n=30)$ & 206 & -0.05 & 0.50 & -0.04 & 0.61 \\
\hline$V v_{\text {(MM/glom) }}(n=43)$ & 165 & 0.11 & 0.14 & 0.12 & 0.13 \\
\hline$V v_{(\mathrm{MC} / \text { glom })}{ }^{\mathrm{c}}(n=20)$ & 216 & 0.02 & 0.74 & -0.00 & 0.95 \\
\hline GBM width $(n=27)$ & 93 & 0.09 & 0.41 & 0.10 & 0.35 \\
\hline$S v_{\text {(PGBM/glom) }}(n=61)$ & 206 & 0.08 & 0.25 & 0.14 & 0.05 \\
\hline Glomerulopathy index $(n=27)$ & 86 & 0.23 & 0.04 & 0.22 & 0.04 \\
\hline
\end{tabular}


Table 3 Relation of CRAE and CRVE at baseline to change in renal endpoint models

\begin{tabular}{|c|c|c|c|c|c|c|c|c|}
\hline \multirow[t]{4}{*}{ Dependent variable } & \multicolumn{8}{|c|}{ Independent variables } \\
\hline & \multicolumn{4}{|l|}{ CRAE per SD } & \multicolumn{4}{|l|}{ CRVE per SD } \\
\hline & \multicolumn{2}{|l|}{ Duration adjusted } & \multicolumn{2}{|c|}{ Multivariate $^{\mathrm{a}}$ adjusted } & \multicolumn{2}{|l|}{ Duration adjusted } & \multicolumn{2}{|c|}{ Multivariate $^{\mathrm{a}}$ adjusted } \\
\hline & Est (SE) & $\begin{array}{l}p \\
\text { value }\end{array}$ & Est (SE) & $\begin{array}{l}p \\
\text { value }\end{array}$ & Est (SE) & $\begin{array}{l}p \\
\text { value }\end{array}$ & Est (SE) & $\begin{array}{l}p \\
\text { value }\end{array}$ \\
\hline Change in GFR & $-0.52(1.15)$ & 0.65 & & & $0.08(1.13)$ & 0.94 & & \\
\hline Change in AER & $0.04(1.39)$ & 0.97 & & & $0.09(1.37)$ & 0.95 & & \\
\hline Change in $V v_{\text {(Mes/glom) }}$ & $0.0051(0.0033)$ & 0.13 & & & $0.0042(0.0033)$ & 0.20 & & \\
\hline Change in $V v_{(\mathrm{MM} / \text { glom })}$ & $0.0045(0.0022)$ & 0.04 & $0.0032(0.0022)$ & 0.14 & $0.0046(0.0021)$ & 0.03 & $0.0033(0.0021)$ & 0.13 \\
\hline Change in $V v_{(\mathrm{MC} / \text { glom })}{ }^{\mathrm{b}}$ & $-0.0003(0.0015)$ & 0.86 & & & $0.0002(0.0015)$ & 0.89 & & \\
\hline Change in $V v_{\text {(Int/cortex) }}$ & $-0.0032(0.0044)$ & 0.46 & & & $0.0040(0.0043)$ & 0.36 & & \\
\hline Change in $V v_{(\mathrm{AT} / \mathrm{TT})}{ }^{\mathrm{c}}$ & $-0.0012(0.0036)$ & 0.73 & & & $-0.0019(0.0035)$ & 0.58 & & \\
\hline $\begin{array}{l}\text { Change in GBM width } \\
(\mathrm{nm})\end{array}$ & $9.30(4.47)$ & 0.04 & $7.29(4.43)$ & 0.10 & $8.06(4.38)$ & 0.07 & $5.03(4.36)$ & 0.25 \\
\hline Change in $S v_{\text {(PGBM/glom) }}$ & $-0.0034(0.0017)$ & 0.05 & $-0.0023(0.0017)$ & 0.18 & $-0.0044(0.0017)$ & 0.01 & $-0.0022(0.0017)$ & 0.18 \\
\hline $\begin{array}{l}\text { Change in } \\
\text { glomerulopathy index }\end{array}$ & $1.38(0.55)$ & 0.01 & $1.06(0.53)$ & 0.05 & $1.27(0.54)$ & 0.02 & $0.81(0.52)$ & 0.12 \\
\hline
\end{tabular}

Values are Est (SE): beta estimate and standard error from linear regression model

Multivariate adjustment was: for change in GBM width $(\mathrm{nm})$ : diabetes duration, $\mathrm{HbA}_{1 \mathrm{c}}$ and sex; for change in glomerulopathy index: diabetes duration, $\mathrm{HbA}_{1 \mathrm{c}}$, sex and drug trial treatment; for change in $S v_{(\mathrm{PGBM} / \mathrm{glom})}$ : diabetes duration, $\mathrm{HbA}_{1 \mathrm{c}}$ and study site; and for change in $V v_{(\mathrm{MM} / \mathrm{glom})}$ : diabetes duration and $\mathrm{HbA}_{1 \mathrm{c}}$

${ }^{a}$ From linear regression model

${ }^{\mathrm{b}}$ Mesangial cell fractional volume/glomerulus; ${ }^{\mathrm{c}}$ volume fraction of cortical tubules per total atrophic tubules

reflect microvascular changes from processes described above independently of diabetic retinopathy severity [3239]. These may be markers of similar changes in the microvascular diameters in the cerebral, coronary, peripheral and renal circulations in persons with or without type 1 diabetes mellitus; they may also be indicators of pathogenetic processes that are damaging to other targets of diabetic microvascular injury $[33,39,40]$.

The RASS is the first study to examine the relationship of CRAE and CRVE with changes in diabetic renal

Table 4 Relation of CRAE and CRVE at baseline to 5-year incidence of renal abnormality models

\begin{tabular}{|c|c|c|c|c|c|c|c|c|}
\hline \multirow[t]{4}{*}{ Incident variable } & \multicolumn{8}{|c|}{ Independent variables } \\
\hline & \multicolumn{4}{|l|}{ CRAE per SD } & \multicolumn{4}{|l|}{ CRVE per SD } \\
\hline & \multicolumn{2}{|l|}{ Duration adjusted } & \multicolumn{2}{|c|}{ Multivariate adjusted $^{\mathrm{a}}$} & \multicolumn{2}{|l|}{ Duration adjusted } & \multicolumn{2}{|c|}{ Multivariate adjusted $^{\mathrm{a}}$} \\
\hline & OR $(95 \% \mathrm{CI})^{\mathrm{b}}$ & $\begin{array}{l}p \\
\text { value }\end{array}$ & OR $(95 \% \mathrm{CI})^{\mathrm{b}}$ & $\begin{array}{l}p \\
\text { value }\end{array}$ & OR $(95 \% \mathrm{CI})^{\mathrm{b}}$ & $\begin{array}{l}p \\
\text { value }\end{array}$ & OR $(95 \% \mathrm{CI})^{\mathrm{b}}$ & $\begin{array}{l}p \\
\text { value }\end{array}$ \\
\hline Abnormal $V v_{\text {(Mes/glom) }}$ & $0.86(0.58-1.27)$ & 0.45 & & & $0.88(0.59-1.31)$ & 0.53 & & \\
\hline Abnormal $V v_{(\mathrm{MM} / \mathrm{glom})}$ & $1.38(0.96-1.98)$ & 0.08 & & & $1.30(0.92-1.85)$ & 0.14 & & \\
\hline Abnormal $V v_{(\mathrm{MC} / \mathrm{glom})}{ }^{\mathrm{c}}$ & $1.03(0.64-1.64)$ & 0.91 & & & $1.00(0.63-1.58)$ & 0.99 & & \\
\hline Abnormal GBM width & $1.36(0.85-2.19)$ & 0.20 & & & $1.38(0.85-2.23)$ & 0.19 & & \\
\hline Abnormal $S v_{(\mathrm{PGBM} / \text { glom })}$ & $1.23(0.90-1.67)$ & 0.19 & & & $1.37(1.01-1.85)$ & 0.04 & $1.07(0.76-1.50)$ & 0.70 \\
\hline Abnormal GI ${ }^{\mathrm{d}}$ & $1.93(1.16-3.20)$ & 0.01 & $1.48(0.76-2.86)$ & 0.25 & $1.81(1.07-3.05)$ & 0.03 & $1.25(0.64-2.45)$ & 0.51 \\
\hline
\end{tabular}

${ }^{\mathrm{a}}$ Multivariate adjustment was: for abnormal $S v_{(\mathrm{PGBM} / \mathrm{glom})}$ : diabetes duration, $\mathrm{HbA}_{\mathrm{lc}}$ and study site; for abnormal glomerulopathy index: diabetes duration, $\mathrm{HbA}_{1 \mathrm{c}}$ and age

${ }^{\mathrm{b}}$ From logistic regression model

${ }^{\mathrm{c}}$ Mesangial cell fractional volume per glomerulus; ${ }^{\mathrm{d}}$ glomerulopathy index 
structural variables in sequential research biopsies in patients with type 1 diabetes mellitus. CRAE and CRVE were associated with abnormalities and increases in renal structural variables that reflect extracellular matrix accumulation, the central pathological processes leading to renal dysfunction in diabetic nephropathy [7, 9]. These abnormalities included: (1) increases in GBM width and mesangial matrix fractional volume, which, as with the composite glomerulopathy index, are closely associated with albuminuria in type 1 diabetes mellitus; and (2) decrease in glomerular filtration surface

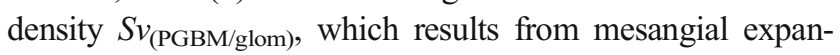
sion [9]; and they are ultimately associated with GFR loss in type 1 diabetes mellitus (Fig. 1) [24].

In the main, these relationships were independent of diabetes duration or severity of diabetic retinopathy. Speculation on these associations could take several directions. Increased CRVE and CRAE could be related to increased retinal blood flow, possibly mirrored by increases in renal blood flow and long posited as a candidate mechanism for diabetic nephropathy pathogenesis through haemodynamic injury [41]. Alternatively, increased retinal and renal blood flow could reflect compensatory responses to metabolic disturbances that could be the drivers of tissue injury in diabetes, e.g. relative tissue hypoxia [42] or oxidative stress [43].

Regardless of the mechanism, the RASS, which directly compares structural changes at relatively early stages of diabetic nephropathy and diabetic retinopathy, provides additional information, which indicates important relationships between these two microvascular complications and could not be derived from renal functional studies, since these were all normal at RASS baseline. It is not clear from these data whether the associations between baseline retinal diameter variables and the change in important structural variables of diabetic nephropathy in type 1 diabetes mellitus patients without renal functional abnormalities will actually make early diabetic nephropathy risk predictions more precise [44]. In contrast to the relationship between baseline CRAE and renal structural change as measured by glomerulopathy index, an increase in CRAE over the 5 years of RASS was inversely related to $V v_{(\mathrm{MM} / \mathrm{glom})}$. Clearly, longer term studies involving larger numbers of type 1 diabetic patients with hypertension and albuminuria would be necessary to further describe and unravel these complex dynamic relationships.

In the RASS, an increase in CRVE was related to an increase in $V v_{\text {(Int/cortex) }}$. The latter is a measure of interstitial expansion, which at these earlier stages of diabetic nephropathy would mainly result from an increase in the cellular component of the interstitium [29]. Wider retinal venules are associated with systemic inflammation, consistent with the finding that the latter may be involved in the early increase in $V v_{\text {(Int/cortex) }}$ [45].
No relationships were found in the RASS between retinal vessel diameters and renal functional endpoints. This was in contrast to findings in type 1 diabetes mellitus patients in the Wisconsin Epidemiologic Study of Diabetic Retinopathy (WESDR) [11]. In that study, the risk of incident proteinuria and renal insufficiency was increased (RR for 4th vs 1 st to 3 rd quartiles $1.53,95 \%$ CI $1.19-1.97$ and $1.41,1.05-2.17$ respectively) in persons with wider retinal venular diameters, the increase being independent of age, sex, duration of diabetes, $\mathrm{HbA}_{1 \mathrm{c}}$, baseline diabetic retinopathy severity and other factors. No relationship was found between retinal arteriolar diameter at baseline and these renal endpoints in that study. Comparisons of RASS findings with those from the WESDR are limited due to differences in the two cohorts. Thus the WESDR reported on functional outcomes in a diabetic cohort including patients with hypertension and microalbuminuria at baseline, whereas the RASS cohort members were all normotensive and normoalbuminuric at baseline. Moreover, WESDR participants were studied in a period of poorer glycaemic control. It can only be conjectured that if the RASS (like the WESDR) had included hypertensive albuminuric patients with longer duration of type 1 diabetes, it might have found stronger associations between retinal vessel diameters and anatomical renal abnormalities.

Our study has a number of strengths, including the objective determination of retinal vessel calibre using standardised protocols and the use of careful morphometric techniques in two research renal biopsies spaced 5 years apart. However, caution should be exercised in interpreting the findings. It is possible that the angiotensin-receptor blocker or ACE inhibitor treatment used in the RASS masked a possible relationship between retinal vessel measurements and renal endpoints. Although neither treatment arm in our study was shown to have a protective effect on structural or functional renal endpoints [46], angiotensin-receptor blocker and ACE inhibitor treatment significantly reduced retinopathy progression in the RASS. This may have limited detection of associations of changes in CRAE or CRVE with renal structural or functional endpoints, which might have been present in a natural history study. However, when analyses were limited to the 85 persons in the placebo group the associations of CRAE or CRVE with the renal endpoints were essentially unchanged (R. Klein, unpublished data). In addition, our study included estimates of CRAE and CRVE taken at a single and random point in the pulse cycle. However, we have previously shown that the effect of variability from the pulse cycle was not large and also not likely to affect any of the associations under study [47]. It is possible that the choice of CRAE as marker of narrowing of retinal arterioles may not have been as sensitive as other measures of structural and physiological changes in the microvasculature, e.g. retinal arteriole wall-to-lumen ratio; 
this could have diminished our ability to demonstrate stronger relationships with renal structural abnormalities [48].

In summary, retinal vessel diameters were related to the early stages of diabetic nephropathy lesion development in terms of matrix accumulation and interstitial expansion, but were unrelated to changes in renal function in normotensive, normoalbuminuric persons with type 1 diabetes mellitus. At this point in time, we can only speculate that widened retinal venular diameter reflects the cumulative effects of various diabetic processes on the systemic microvasculature, including the kidney. However, it is too early to use this measure clinically to determine risk of renal anatomical damage prior to the appearance of functional changes, e.g. albuminuria and decreasing glomerular filtration, in people with type 1 diabetes.

Acknowledgements This study was funded by research grants from the Juvenile Diabetes Research Foundation (R. Klein) and the National Institutes of Health (NIH), National Institute of Diabetes and Digestive and Kidney Disease (NIH DK51975). Work was also supported by Merck (in the USA), Merck Frosst (in Canada) and the Canadian Institutes of Health Research (CIHR) (DCT 14281). The University of Minnesota General Clinical Research Center is supported by the NIH (M01 RR 00400). Additional support was given by the National Institutes of Health, National Eye Institute (EY12198) and Research to Prevent Blindness (Senior Scientific Investigator Award to R. Klein) (New York, USA). S. Suissa was the recipient of a Distinguished Investigator Award from the CIHR. The sponsors and funding organisations had no role in the design or conduct of this research.

Duality of interest $\quad$ B. Zinman has received lecture fees, consulting fees and research grants from Merck. R. Klein is an Advisory Board member for AstraZeneca (through the DIRECT study), Pfizer, Lilly and Novartis. All other authors declare that there is no duality of interest associated with this manuscript.

\section{References}

1. National Institutes of Health (2006) U.S. Renal Data System, USRDS 2006 annual data report: atlas of end-stage renal disease in the United States. National Institutes of Health, National Institute of Diabetes and Digestive and Kidney Diseases, Bethesda

2. Reddi AS, Camerini-Davalos RA (1990) Diabetic nephropathy. An update. Arch Intern Med 150:31-43

3. Raptis AE, Viberti G (2001) Pathogenesis of diabetic nephropathy. Exp Clin Endocrinol Diab 109(Suppl 2):S424-S437

4. Jawa A, Kcomt J, Fonseca VA (2004) Diabetic nephropathy and retinopathy. Med Clin N Am 88:1001-1036

5. Gross JL, de Azevedo MJ, Silveiro SP, Canani LH, Caramori ML, Zelmanovitz T (2005) Diabetic nephropathy: diagnosis, prevention, and treatment. Diab Care 28:164-176

6. Rossing P (2006) Prediction, progression and prevention of diabetic nephropathy. The Minkowski Lecture 2005. Diabetologia 49:11-19

7. Caramori ML, Fioretto P, Mauer M (2006) Enhancing the predictive value of urinary albumin for diabetic nephropathy. J Am Soc Nephrol 17:339-352
8. Fioretto P, Steffes MW, Mauer M (1994) Glomerular structure in nonproteinuric IDDM patients with various levels of albuminuria. Diabetes 43:1358-1364

9. Mauer SM, Steffes MW, Ellis EN, Sutherland DE, Brown DM, Goetz FC (1984) Structural-functional relationships in diabetic nephropathy. J Clin Invest 74:1143-1155

10. Klein R, Zinman B, Gardiner R et al (2005) The relationship of diabetic retinopathy to preclinical diabetic glomerulopathy lesions in type 1 diabetic patients: the Renin-Angiotensin System Study. Diabetes 54:527-533

11. Wong TY, Shankar A, Klein R, Klein BE (2004) Retinal vessel diameters and the incidence of gross proteinuria and renal insufficiency in people with type 1 diabetes. Diabetes 53:179-184

12. Klein R, Klein BE, Moss SE, Wong TY (2007) Retinal vessel caliber and microvascular and macrovascular disease in type 2 diabetes: XXI. The Wisconsin Epidemiologic Study of Diabetic Retinopathy. Ophthalmology 114:1884-1892

13. Mauer M, Zinman B, Gardiner R et al (2002) ACE-I and ARBs in early diabetic nephropathy. J Renin Angiotensin Aldosterone Syst 3:262-269

14. Early Treatment Diabetic Retinopathy Study Research Group (1991) Grading diabetic retinopathy from stereoscopic color fundus photographs - an extension of the modified Airlie House classification. ETDRS report number 10. Ophthalmology 98 (Suppl):786-806

15. Klein R, Klein BE, Magli YL et al (1986) An alternative method of grading diabetic retinopathy. Ophthalmology 93:1183-1187

16. Hubbard LD, Brothers RJ, King WN et al (1999) Methods for evaluation of retinal microvascular abnormalities associated with hypertension/sclerosis in the Atherosclerosis Risk in Communities Study. Ophthalmology 106:2269-2280

17. Knudtson MD, Lee KE, Hubbard LD, Wong TY, Klein R, Klein BE (2003) Revised formulas for summarizing retinal vessel diameters. Curr Eye Res 27:143-149

18. Gaspari F, Perico N, Matalone M et al (1998) Precision of plasma clearance of iohexol for estimation of GFR in patients with renal disease. J Am Soc Nephrol 9:310-313

19. Gaspari F, Perico N, Remuzzi G (1998) Application of newer clearance techniques for the determination of glomerular filtration rate. Curr Opin Nephrol Hypertens 7:675-680

20. Chavers BM, Simonson J, Michael AF (1984) A solid phase fluorescent immunoassay for the measurement of human urinary albumin. Kidney Int 25:576-578

21. The Diabetes Control and Complications Trial Research Group (1993) The effect of intensive treatment of diabetes on the development and progression of long-term complications in insulin-dependent diabetes mellitus. The Diabetes Control and Complications Trial Research Group. N Engl J Med 329:977-986

22. Donnelly S, Goodyer P, Mauer M (2008) Comparing the automated vs manual method of needle biopsy for renal histology artefacts. Nephrol Dial Transplant 23:2098-2100

23. Brito PL, Fioretto P, Drummond K et al (1998) Proximal tubular basement membrane width in insulin-dependent diabetes mellitus. Kidney Int 53:754-761

24. Ellis EN, Steffes MW, Goetz FC, Sutherland DE, Mauer SM (1986) Glomerular filtration surface in type I diabetes mellitus. Kidney Int 29:889-894

25. Jensen EB, Gundersen HJ, Østerby R (1979) Determination of membrane thickness distribution from orthogonal intercepts. J Microsc 115:19-33

26. Steffes MW, Barbosa J, Basgen JM, Sutherland DE, Najarian JS, Mauer SM (1983) Quantitative glomerular morphology of the normal human kidney. Lab Invest 49:82-86

27. Steffes MW, Bilous RW, Sutherland DE, Mauer SM (1992) Cell and matrix components of the glomerular mesangium in type I diabetes. Diabetes 41:679-684 
28. Rudberg S, Osterby R, Østerby R, Dahlquist G, Nyberg G, Persson B (1997) Predictors of renal morphological changes in the early stage of microalbuminuria in adolescents with IDDM. Diab Care 20:265-271

29. Katz A, Caramori ML, Sisson-Ross S, Groppoli T, Basgen JM, Mauer M (2002) An increase in the cell component of the cortical interstitium antedates interstitial fibrosis in type 1 diabetic patients. Kidney Int 61:2058-2066

30. Klein R, Klein BE, Moss SE et al (2003) Retinal vascular abnormalities in persons with type 1 diabetes. The Wisconsin Epidemiologic Study of Diabetic Retinopathy: XVIII. Ophthalmology 110:2118-2125

31. Klein R, Klein BE, Moss SE et al (2004) The relation of retinal vessel caliber to the incidence and progression of diabetic retinopathy: XIX. The Wisconsin Epidemiologic Study of Diabetic Retinopathy. Arch Ophthalmol 122:76-83

32. Wise GN, Dollery CT, Henkind P (1971) The retinal circulation. Harper and Row, New York, pp 325-348

33. Wells RE, Herman M, Gorlin R (1966) Microvascular changes in coronary heart disease. Circulation 237:33-34

34. Wendland JP (1966) Retinal arteriolosclerosis in age, essential hypertension, and diabetes mellitus. Trans Am Ophthalmol Soc 64:735-761

35. Dollery CT, Ramalho PS, Patterson JW (1966) Retinal vasculary alterations in hypertension. In: Gross F (ed) Antihypertensive therapy; principles and practice, and international symposium. Springer, New York, pp 152-169

36. Tso MO, Abrams GW, Jampol LM (1991) Hypertensive retinopathy, choroidopathy, and optic neruopathy: clinical and pathophysiological approach to classification. In: Singerman LJ, Jampol LM (eds) Retinal and choroidal manifestations of systemic disease. Williams and Wilkins, Baltimore, pp 79-127
37. Tso MO, Jampol LM (1982) Pathophysiology of hypertensive retinopathy. Ophthalmology 89:1132-1145

38. Apple DJ, Naumann GO (1986) Retina. In: Naumann GO, Apple DJ (eds) Pathology of the eye. Springer, New York, pp 580-583

39. Goto I, Katsuki S, Ikui H, Kimoto K, Mimatsu T (1975) Pathological studies on the intracerebral and retinal arteries in cerebrovascular and noncerebrovascular diseases. Stroke 6:263-269

40. Carlson EC (1994) Scanning and transmission electron microscopic studies of normal and diabetic acellular glomerular and retinal microvessel basement membranes. Microsc Res Tech 28:165-177

41. Carmines PK (2010) The renal vascular response to diabetes. Curr Opin Nephrol Hypertens 19:85-90

42. Williamson JR, Chang K, Frangos M et al (1993) Hyperglycemic pseudohypoxia and diabetic complications. Diabetes 42:801-813

43. Forbes JM, Fukami K, Cooper ME (2007) Diabetic nephropathy: where hemodynamics meets metabolism. Exp Clin Endocrinol Diab 115:69-84

44. Hovind P, Rossing P, Tarnow L, Smidt UM, Parving HH (2001) Progression of diabetic nephropathy. Kidney Int 59:702-709

45. Schlondorff DO (2008) Overview of factors contributing to the pathophysiology of progressive renal disease. Kidney Int 74:860-866

46. Mauer M, Zinman B, Gardiner R et al (2009) Renal and retinal effects of enalapril and losartan in type 1 diabetes. N Engl J Med 361:40-51

47. Knudtson MD, Klein BE, Klein R et al (2004) Variation associated with measurement of retinal vessel diameters at different points in the pulse cycle. Br J Ophthalmol 88:57-61

48. Ritt M, Harazny JM, Ott C et al (2009) Wall-to-lumen ratio of retinal arterioles is related with urinary albumin excretion and altered vascular reactivity to infusion of the nitric oxide synthase inhibitor $N$-monomethyl-L-arginine. J Hypertens 27:2201-2208 